\title{
Peirce Knew Why Abduction Isn't IBE-A Scheme and Critical Questions for Abductive Argument
}

\author{
Shiyang $\mathrm{Yu}^{1} \cdot$ Frank Zenker $^{1,2,3,4}$ (D)
}

Published online: 29 November 2017

(C) The Author(s) 2017. This article is an open access publication

\begin{abstract}
Whether abduction is treated as an argument or as an inference, the mainstream view presupposes a tight connection between abduction and inference to the best explanation (IBE). This paper critically evaluates this link and supports a narrower view on abduction. Our main thesis is that merely the hypothesis-generative aspect, but not the evaluative aspect, is properly abductive in the sense introduced by C. S. Peirce. We show why equating abduction with IBE (or understanding them as inseparable parts) unnecessarily complicates argument evaluation by levelling the status of abduction as a third reasoning mode (besides deduction and induction). We also propose a scheme for abductive argument along with critical questions, and suggest retaining abduction alongside IBE as related but distinct categories.
\end{abstract}

Keywords Abduction - Abductive argument - Critical questions · Inference to the best explanation $\cdot$ Peirce $\cdot$ Scheme

\section{Introduction}

Introduced by Charles Sanders Peirce (1839-1914), 'abduction' refers to the creative generation of explanatory hypotheses. The term denotes an inference that is "frequently employed, in some form or other, both in everyday and in scientific

Frank Zenker

frank.zenker@fil.lu.se

1 Department of Philosophy, Institute of Logic and Cognition, Sun Yat-sen University, 135 Xingang Road West, Guangzhou, People's Republic of China

2 Philosophy and Cognitive Science, Lund University, 22100 Lund, Sweden

3 Institute of Philosophy, SAS, Klemensova 19, 81364 Bratislava, Slovakia

4 Department of Philosophy, Konstanz University, Postfach, D9, 78457 Constance, Germany 
reasoning" (Douven 2011, 1). With important exceptions and qualification (e.g., Spohn 2012; Woods 2013), many view abduction as the strongest candidate for a third top level inference-type besides deduction and induction, aka 'reasoning of the third kind', or assign to it a crucial role in scientific and common-sense reasoning (e.g., Preyer and Mans 1999, 12; Walton 2001, 142).

AI researchers, for instance, currently pay attention to abductive inference in the context of medical and legal reasoning (e.g., Josephson and Josephson 1994; Bex and Verheij 2012, 2013). Argumentation scholars, by contrast, study the linguistic forms that articulate this inference in reasoned discourse, for which they postulate argumentation schemes and associated critical questions (Walton et al. 2008; Wagemans 2014). Regardless of whether abduction is treated as an argument or as an inference, the bulk of the literature presupposes a tight connection between abduction and inference to the best explanation (IBE).

Our purpose in this paper is to critically evaluate this link, and to argue for a narrower view on abduction than the mainstream literature suggests. We review abduction and inference to the best explanation (Sect. 2), trace how abduction came to be viewed as IBE (Sect. 3), then present abduction in Peirce's sense, and propose a schema with critical questions (Sect. 4). We offer our conclusions in Sect. 5.

\section{Abduction Versus Inference to the Best Explanation}

\subsection{Overview}

This section presents canonical examples of abduction (2.2), reviews representative contributions from informal logic, pragma-dialectics, and artificial intelligence (2.3), points out the link between abduction and IBE (2.4), and identifies a regular IBE tradition (2.5).

\subsection{Examples of Abductive Inference}

The first two examples could occur in everyday conversation, the third is typical for a scientific context:

You happen to know that Tim and Harry have recently had a terrible row that ended their friendship. Now someone tells you that she just saw Tim and Harry jogging together. The best explanation for this that you can think of is that they made up. You conclude that they are friends again (Douven 2011, 1).

I once landed at a seaport in a Turkish province; and, as I was walking up to the house which I was to visit, I met a man upon horseback, surrounded by four horsemen holding a canopy over his head. As the governor of the province was the only personage I could think of who would be so greatly honored, I inferred that this was he (Peirce, 2.625). ${ }^{1}$

\footnotetext{
${ }^{1}$ References to Peirce's work are to The Collected Papers of Charles Sanders Peirce (1931-1958), bracketed numbers refer to volume and paragraph.
} 
Fossils are found; say, remains like those of fishes, but far in the interior of the country. To explain the phenomenon, we suppose the sea once washed over this land (Peirce, 2.625).

In each example an explanandum is mentioned, and an explanans is inferred. Notice that, unlike in Peirce's examples, Douven qualifies the conclusion as the best possible explanandum (we return to these examples in Sect. 2.4).

\subsection{Three Argument Schemes for Abduction}

As a crucial concept in argumentation theory, an argument scheme roughly corresponds to a classical topos (Perelman and Olbrechts-Tyteca 1969; van Eemeren and Grootendorst 1992; Walton 1996; van Eemeren et al. 2014). It provides "an abstract characterization of the way in which in a particular type of argumentation a premise used in support of a standpoint is related to that standpoint in order to bring about a transfer of acceptance from that premise to the standpoint" (van Eemeren et al. 2014, 19).

Argumentation schemes generate evaluative potential in virtue of their associated critical questions (CQs). Answering a scheme's CQs positively for a schemeinstance fulfills a necessary condition to transfer the acceptability of the premises to the conclusion. ${ }^{2}$ So if stated premises are deemed acceptable, this creates a warranted expectation, or presumption, that a respondent who continues to doubt the conclusion present reasons to support her stance.

In discussing the "abductive argumentation scheme" as a species of the genus "inference to the best explanation" (IBE), Walton (2001; see Walton et al. 2008) characterizes three stages of abductive inference. It "begins from a set of premises that report observed findings or facts-the known evidence in a given case," upon which one "searches [...] among various explanations [...] for these facts," and finally "selects out the so-called 'best' explanation and draws a conclusion that the selected explanation is acceptable as a hypothesis" (Walton 2001, 144).

He distills the three steps into this scheme (ibid., 162),

$F$ is a finding or given set of facts.

$E$ is a satisfactory explanation of $F$.

No alternative explanation $E^{\prime}$ given so far is as satisfactory as $E$.

Therefore, $E$ is plausible, as a hypothesis.

and evaluates instances of the abductive scheme in a dialogue model, using these CQs (ibid., 162):

\footnotetext{
2 Answering a scheme's CQs positively for a given scheme-instance could be a sufficient condition only if the CQs were complete and correct, in the sense of being perfectly sensitive to an instance's semantic content. But CQs are normally proposed for a scheme, rather than its instance(s). So evaluating schemeinstances requires case-by-case decisions regarding such sensitivity.
} 
CQ1: [Absolute merits of explanation:] How satisfactory is $E$ as an explanation of $F$, apart from the alternative explanations available so far in the dialogue?

CQ2: [Relative merits of explanation:] How much better an explanation is $E$ than the alternative explanations available so far in the dialogue?

CQ3: [Relative developmental state of dialogue:] How far has the dialogue progressed? If the dialogue is an inquiry, how thorough has the search been in the investigation of the case?

CQ4: [Comparative merit of continuing the dialogue:] Would it be better to continue the dialogue further, instead of drawing a conclusion at this point?

Walton's CQs are based on criteria proposed by Josephson and Josephson (1994), given below. Notice that, because in each of these CQs one can replace 'dialogue' by 'explanation' without loss of significance, the former term merely reflects Walton's preferred theoretical perspective.

Addressing abduction from the pragma-dialectical perspective (van Eemeren and Grootendorst 1992, 2004; Hitchcock and Wagemans 2011), Wagemans (2014) studies the relation between the abductive scheme's premises and its critical questions, though calling it 'pattern of argumentation based on abduction' rather than 'scheme'. It consists of two arguments, where ' 1 ' marks the standpoint, ' 1.1 ' the main argument, ' 1.1 ' expresses the justificatory force of 1.1 , where the substandpoint $1.1^{\prime}$ is supported by $1.1^{\prime} .1$ and $1.1^{\prime} .1^{\prime}$.

1 It may be hypothesized that $X i$.

$1.1 \quad$ It is observed that $Y$.

1.1' Of possible explanations $X_{1}-X_{n}, \mathrm{X}_{\mathrm{i}}$ is the best explanation of $Y$.

1.1'.1 $X_{i}$ meets criteria $C_{1}-C_{n}$ with scores $S_{1}-S_{n}$.

$1.1^{\prime} .1^{\prime} \quad$ Decision rule $R$ applies.

Wagemans $(2014,6)$

Wagemans' pattern prima facie improves Walton's scheme because “"generative' as well as 'selective' abduction have their place [in it]" (ibid., 6). (For these terms, see Aliseda 2006.) Quoting Douven's (2011) remark on abduction, Wagemans submits that abduction should be viewed "not so much as a process of inventing hypotheses but rather as one of adopting hypotheses $[\ldots]$ as $[\ldots]$ worthy candidate[s] for further investigation" (Wagemans, after Douven; ibid., 3). Both thus suggest that abduction has two aspects, and Wagemans accordingly offers a "generative" and a "selective definition" that he draws into a single scheme, reserving 'IBE' for the selective aspect.

In the following, our main claim is that merely the generative aspect is properly abductive in Peirce's sense, and that the selective aspect marks an important distinction between abduction and IBE. 
Walton cites Josephson and Josephson (1994), who characterize "[a]bduction, or inference to the best explanation, [as] a form of inference that goes from data describing something to a hypothesis that best explains or accounts for the data" (ibid., 5). They offer this pattern:

$D$ is a collection of data (facts, observations, givens).

$H$ explains $D$ (would, if true, explain $D$ ).

No other hypothesis can explain $D$ as well as $\mathrm{H}$ does.

Therefore, $H$ is probably true.

and also provide a list of "considerations" (ibid., 14), here reformulated as critical questions:

1. Threshold How decisively does $\mathrm{H}$ surpass the alternatives?

2. Internal merit How good is $\mathrm{H}$ by itself, independently of considering alternatives?

3. Data reliability How trustworthy are data, respectively the processes by which data were obtained?

4. Exhaustiveness How much confidence is there that all plausible explanations have been considered?

5. Cost and Benefits What pragmatic considerations matter, including the costs of being wrong, and the benefits of being right?

6. Gravity of issue How strong is the need to reach a conclusion, especially considering the possibility of seeking further evidence before deciding?

We discuss these critical questions below (Sect. 4.3). Presently, notice that Wagemans' approach connects the hypothesis-generative aspect of abduction to the hypothesis-selective aspect of IBE. By contrast, Josephson and Josephson as well as Walton integrate abduction with IBE, making the former a part of the latter. In fact, they sometimes seem to treat both aspects as one.

We go on to discuss reasons for linking abduction with IBE.

\subsection{What Links Abduction with IBE?}

Walton appears to accept the link between abduction and IBE on the authority of Gilbert Harman (1965), who is regarded to have established IBE as a theoretical category. Harman indeed states that " 'inference to the best explanation' corresponds approximately to what others have called 'abduction'" (Harman 1965, 88; italics added). However, his paper uses the term 'abduction' once-in the quote provided-but does not offer a substantial remark. Moreover, Walton appears to hold that the abduction-IBE-link squares with Peirce's own understanding of abduction. For he lists both of Peirce's examples (Sect. 2.2), and claims they are easily seen to follow the IBE pattern. Similarly, Wagemans starts "from the idea that abduction plays a key role in the process of finding explanations of observed facts." Though distinguishing generative and selective aspects, he also acknowledges "a tradition in which abduction is described as a form of reasoning that 
involves the process of selection" (Wagemans 2014, 3). Josephson and Josephson finally define abduction as IBE from the outset. ${ }^{3}$

A first reason for linking abduction with IBE thus refers to a tradition originating with Harman, a second (re)states Harman's contention that both terms are approximately synonymous, and a third cites Peirce's own work in support of this synonymy. We treat the third reason first, for the second stands or falls with evaluating it, then return to the first reason.

In Peirce's examples (see Sect. 2), the fossil case offers the hypothesis (or supposition) that "the sea once [regularly] washed over this land," but does not compare it with another hypothesis (e.g., fish being washed inland once by a typhoon, or their remains being left behind by preying birds). Similarly, Peirce's second example does not compare the focal hypothesis with other explanations why one might be "surrounded by four horsemen." So it remains unclear why sea having once washed over land, or being the provincial governor, are the best explanatory hypotheses for these observations. Indeed, both examples, as well as text to which they are appended, fail to support that Peirce treated abduction as IBE by another name.

This provides sufficient grounds to also find the second reason unsupported, leaving the appeal to an IBE-tradition. So does Harman's view on IBE (as approximately corresponding to Peirce's view on abduction) reflect an IBE tradition?

\subsection{What IBE Tradition?}

Though relevant to several fields, the core of the theoretical discussion on abduction is in philosophy of science (Hintikka 1998; Aliseda 2006; Williamson 2003; Schurz 2008). In stating that "[...] many others contend that abduction, construed as inference to the best explanation, is an essential part of scientific and everyday reasoning (Magnani 2001; Psillos 2000; Thagard 1992, 1999, 2000)," Thagard (2007, 229; italics added) names some contributors to the IBE tradition. Thagard included, these authors presuppose that abduction is (approximately) synonymous with IBE, or support this view-misleadingly, as we saw-with reference to Peirce.

Thagard (2007) states that "Peirce [...] used the term 'abduction' to refer to a kind of inference that involves the generation and evaluation of explanatory hypotheses" (Thagard 2007, 226; italics added), and thus "[...] to infer[ing] a hypothesis because it really is the best explanation of all the available evidence" (ibid., 4). Psillos (2000) holds the same view. Although Thagard notes that Shelley (1996) allegedly extended the meaning of 'abduction' in Peirce's sense, Shelley submits that Peirce's own figure already "describes the inference to [...] the best explanation [...]" (Shelley, 1996, 280f.). The forgoing at any rate provides sufficient grounds to speak of a regular IBE tradition, even if it misconstrues its origin.

Magnani (2001) moreover distinguishes theoretical (including selective sentential and creative model-based) abduction from manipulative abduction. The latter

\footnotetext{
${ }^{3}$ For an example of work that withstands the temptation to connect abduction with IBE, see Bex and Verheij $(2013,259)$.
} 
term refers to "an extra-theoretical behavior that aims at creating communicable accounts of new experiences to integrate them into previously existing systems of experimental and linguistic (theoretical) practices" (ibid., 53). Though avoiding a claim to have inherited this distinction from Peirce, also he subsumes generation and evaluation of hypotheses under 'abduction'. In fact, Magnani challenges Peirce's view by regarding hypothesis-conjecture and -evaluation as inseparable and intertwined processes. (We return to this in Sect. 3.3).

To further support that the IBE tradition over-interprets 'abduction', we now turn to how Peirce's original sense of it changed.

\section{How Abduction Became IBE}

\subsection{Overview}

This section traces the development of Peirce's view on abduction (3.2), treats Magnani's challenge (3.3), introduces Lipton's sense of IBE (3.4), compares it with Peirce's sense of abduction (3.5), and notes what is lost were both senses equated (3.6). On this basis, Sect. 4 develops an argument scheme for abduction.

\subsection{The Development of Peirce's Sense of 'Abduction'}

Despite others having discussed abduction before Peirce, he provided the most influential interpretation, at times referring to abduction also as 'retroduction' or 'presumption'. His scholarship spans an early and a late period, but the distinction between abduction, induction, and deduction as "three fundamental modes of argument" (2.103) is found throughout.

The early Peirce treats inference as an "evidencing process," that is, a mode of deciding for or against accepting a hypothesis. Then working within a narrow syllogism model, Peirce distinguishes three "basic kinds of reasoning" (Peirce, 2.623) that alternatively configure a rule, a case, and a result:

Deduction is an inference of a result from a rule and a case:

Rule-All the beans from this bag are white.

Case-These beans are from this bag.

$\therefore$ Result-These beans are white.

Induction is the inference of a rule from a case and a result:

Case-These beans are from this bag.

Result-These beans are white.

$\therefore$ Rule-All the beans from this bag are white. 
Hypothesis(-abduction) is the inference of a case from a rule and a result:

Rule-All the beans from this bag are white.

Result-These beans are white.

$\therefore$ Case-These beans are from this bag.

Deduction is explicative while induction and abduction are ampliative. After all, semantic content following the conclusion indicator (' $\because$ ') will in deductive inference not go beyond the content stated in the premise-set, while the opposite holds in inductive and abductive inference. On the criterion of a semantic contentdifference between premises and conclusion alone, therefore, the distinction between abduction and induction is not obvious.

Anderson (1986) correctly points out that "[i]nduction and abduction [...] both add something new to thought: both provide possible or probable knowledge about an undetermined future," which is to say that "the special role of abduction [...] was not essentially different from that of induction" (ibid., 148f., italics added). Indeed, the early Peirce viewed abduction as a special case of induction, since both forms share the same functions and principles (see Peirce, 2.632). In his later work, however, the syllogistic context proved overly narrow to account for all ampliative forms of scientific reasoning. The late Peirce widened his view of inference to include evidencing and methodological processes (see Burks 1946, 301), holding that:

Induction is an Argument which sets out from a hypothesis, resulting from a previous Abduction, and from virtual predictions, drawn by Deduction, of the results of possible experiments, and having performed the experiments, [which] concludes that the hypothesis is true in the measure in which those predictions are verified [...] (Peirce, 2.96).

This marks a shift away from narrowly considering the evidencing process, towards considering various stages of scientific inquiry. But since the early Peirce already "acknowledge[d] the other aspect of abduction [namely]: its function as a source of new hypotheses," Anderson (1986) correctly points out that "the shift is not simply from evidence process to source of new ideas," but rather "from a conflation of these two ideas to a particular emphasis on the latter" (ibid., 147f.; italics added).

In fact, Peirce distinguished his three types of reasoning (viz., deduction, induction, abduction) by assigning to each a separate function in the three stages of scientific inquiry. Abduction remains "the process of forming an explanatory hypothesis [and is] the only logical operation which introduces any new idea" (Peirce, 5.171). As before, "deduction merely evolves the necessary consequences of a pure hypothesis" (ibid.). But unlike before, Peirce now qualifies induction as "do[ing] nothing but determine a [truth-]value" (ibid.). So induction tests a

\footnotetext{
${ }^{4}$ For a contrasting attempt to construe deduction as a limiting case of induction, and this in turn as a limiting case of conduction, see Zenker (2011).
} 
hypothesis (or the prediction deduced from it) and determines whether the hypothesis is true, or not. ${ }^{5}$

Peirce's view on inference develops in parallel with his understanding of logic maturing. Having initially viewed logic as little else but "static maxims of a system" - as some continue to view it today-he later treated it, more broadly, "as a method of reasoning, or method of methods" (Anderson 1986, 154). Indeed, the late Peirce viewed abduction as "both a logical form and a lived process" (ibid., 150). But in none of this can we find textual evidence that it was Peirce who linked abduction to IBE.

We may thus note that Peirce did not articulate hypothesis-selection (as opposed to hypothesis-generation) as an aspect of abduction. We now return to Magnani's challenge (Sect. 2.5)

\subsection{Magnani’s Challenge}

Magnani's (2001) distinction between theoretical and manipulative abduction follows upon his criticizing Peirce's treatment of deduction, induction, and abduction as unclear. Magnani submits that, since an infinite number of hypotheses can subsume a data-set-including speculative metaphysical hypotheses one cannot readily verify or falsify-it is impractical to conjecture and evaluate every datasaving hypothesis. Rather, one conjectures hypotheses likely to "check out," i.e., those chancing a positive evaluation. But this allegedly renders vague the distinction between abduction as a conjectural aspect and induction as an evaluative one. Magnani therefore suggests that hypothesis-conjecture and -evaluation occur as one inseparable process.

Understood in a very broad sense, evaluation does of course occur at all times, and with any type of reasoning. In the context of Peirce's induction versus abduction distinction, however, we saw that 'evaluation' narrowly refers to induction. So it is not clear how Magnani's distinction can draw support from a sound criticism of Peirce's view. An example may help to see this. Returning to Douven's example (Sect. 2), suppose someone offers "This flower smells nice" as an explanatory hypothesis for the datum "Tim and Harry are jogging together." That hypothesis is unlikely to "check out." But notice that one must nevertheless have conjectured it before arriving at this judgment. However, one may conjecture the same hypothesis without having to evaluate it, for one may exercise epoché. So the entailment holds in one direction: evaluation presupposes conjecture, but not vice versa.

Moreover, Peirce did address an issue close to Magnani's infinite number of hypotheses. He held that "the human mind's having such a power of guessing right that before very many hypotheses shall have been tried, intelligent guessing may be expected to lead us to the one [hypothesis] which will support all tests, leaving the vast majority of possible hypotheses unexamined" (Peirce, 6.530). But this is "not,

\footnotetext{
5 Compare Bybee (1996), who suggests that scientific inquiry does not "follow a single, specific pattern with identifiable stages [...]" to which one could "legitimately ascribe one and only one inferential structure," wherefore, even if "abduction is the inference of conjecture" in a structural sense, it maywhen viewed functionally-nevertheless "legitimately justify conclusions" (ibid., 41).
} 
and cannot be, the application of abductive reasoning" (Frankfurt 1958, 596). Rather, human guessing power may be explained by the characteristics of a hypothesis. For Peirce states that "[b]y a hypothesis, I mean, not merely a supposition about an observed object [...]" (Peirce, 6.525), but, as Frankfurt (1958, 596) points out, "it is also a 'supposed truth'." So a Peircean hypothesis is more than a possible explanation. It needs to be plausible as well.

For instance, if one finds the road wet in the morning, something as absurd as "gasoline rain" could explain it. Under normal conditions, however, this offers a remote possibility rather than a plausible explanation. This reflects an "economy of research"-principle, providing an order in which hypotheses are tested, and may even exclude less plausible hypotheses from testing (Fig. 1). Differences in belief and background knowledge, of course, make it difficult to draw a boundary between the possible and the plausible. But all we need to show here is that, while the set of possible hypotheses may be infinite, the set of plausible hypotheses is not.

In sum, we fail to conclude that Peirce's distinction between conjecture and evaluation is unclear. At any rate, Magnani's argument does not show this.

\subsection{IBE Again}

Harman (1965) had described IBE as an inference "from the premise that a given hypothesis would provide a 'better' explanation for the evidence than would any other hypothesis, to the conclusion that the given hypothesis is true" (Harman 1965, 89; italics added). By contrast, most scholars today adopt Lipton's (1991) IBE model. This sheds the predicate 'is true', and distinguishes actual from potential, and likeliest from loveliest explanations (Lipton 1991, 59; see Campos 2011, 433). Here, the likeliest explanation is the evidentially most warranted one; the loveliest explanation is that "which would, if correct, be the most explanatory or provide the most understanding" (Lipton 1991, 61, italics added; see Campos 2011, 434).

The question how we may quantify similar magnitudes aside (see the literature on verisimilitude, e.g., Oddie 2016), "likeliness [thus] speaks of truth; loveliness of potential understanding" (Lipton 1991, 61, italics added). But neither likeliness nor loveliness denote, or entail, the truth of the selected hypothesis. In fact, since the merit of an explanans, for Lipton, consists in our potentially improved understanding of the explanandum, already plausible (rather than true) explanations may have explanatory value. The central statement of his IBE model, then, is this:

Given our data and our background beliefs, we infer what would, if true, provide the best of the competing explanations we can generate for those data (so long as the best is good enough for us to make any inference at all) (Lipton 1991, 58; italics added).

Lipton's model improves Harman's, for IBE now features two processes rather than one. According to Lipton, one generates a range of hypotheses each of which potentially explains relevant data. Subsequently, one chooses the loveliest explanation, which thus invokes both the process and the result of what Peirce called 'testing'. So "generating lovely hypotheses and [...] evaluating their 
Fig. 1 The best hypothesis as one candidate in the set of plausible hypotheses, itself a subset of the set of possible hypotheses

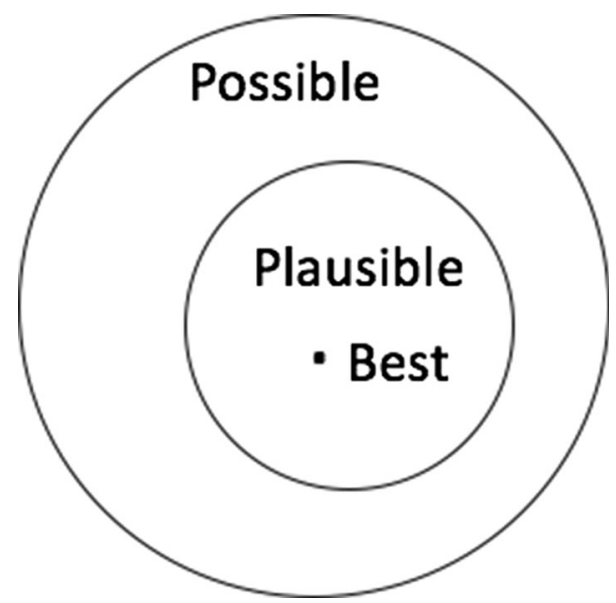

likeliness [...] [comprises] a mixture of two distinct forms of inference with two different aims" (Campos 2011, 441). ${ }^{6}$

The three argument schemes discussed above (Sect. 2.3) are thus seen to follow Lipton's, rather than Harman's IBE model. We proceed to detail the differences to Peirce's view on abduction.

\subsection{IBE Versus Peirce's Abduction}

As a mixed form of abductive and inductive inference, we saw that IBE comprises a hypothesis-generative and a hypothesis-evaluative (or selective) aspect. But only the first aspect corresponds to Peirce's sense of abduction.

To provide a second example, the pyramids are (rightly) esteemed as architectonic masterpieces. Suppose someone who seeks to explain their construction generates a number of hypotheses, some of which might not be properly scientific. So long as the generated hypotheses seem plausible, however, each equally qualifies as resulting from abduction. After all, abduction does not require, nor does it entail, a preference ordering over plausible hypothesis; only IBE requires hypothesis-selection criteria.

This difference between abduction and IBE also suffices to understand why one might view 'abduction as hypothesis-generation' as a third reasoning mode (besides deduction and induction) to begin with. For Lipton's model shows that IBE goes beyond abduction by requiring a systematic selection among potential explanations. When correctly understood, abduction is thus seen to be accompanied by induction and deduction (though it need not be so accompanied). This suggests that, insofar as

\footnotetext{
${ }^{6}$ For the relation between induction and likeliness, see Campos $(2011,434 \mathrm{f}$.), who states that evaluating "the likeliness of a hypothesis [occurs] by way of inductive probability [...] in which we weigh the relative support that all of the empirical data provide for one or the other hypothesis" (ibid.) By contrast, in evaluating the loveliness of the hypothesis, we use its explanatory plausibility, in which "we judge how well an explanation coheres with our current system of beliefs, that is, with our background theoretical knowledge, and with what we perceive or think to be possible" (ibid.).
} 
a reasoning method comprises several reasoning modes, or types, IBE is a reasoning method, and abduction one of its constitutive modes.

Viewed as a mode and a method, abduction and IBE respectively pursue the telos of generating potential explanations and selecting the best among them. Indeed, Peirce demanded that an abduced hypothesis give rise to its own testable experimental or experiential consequences (see Sect. 4). But this fails as a general criterion for IBE, because some instances of hypothesis-comparison and hypothesis-selection can proceed without giving rise to such consequences. An atheist, for instance, may reject the hypothesis that 'God built the pyramids' as the best one, given her own selection criteria. But she may nevertheless find, it is the best hypothesis given other's selection criteria. Since the divine hypothesis generates the same experimental and experiential consequences as an empirically-testable non-divine hypothesis, however, the former is not an abductive hypothesis in Peirce's sense.

Though we can now conclude yet more firmly that Peirce's abduction isn't IBE, one might object that abduction should amount to IBE. We briefly turn to this conjecture.

\subsection{What is Lost were Abduction Equated with IBE}

Equating abduction with IBE incurs a number of non-trivial drawbacks. First, like induction and deduction, abduction was said to be a mode of reasoning, while IBE was a method. So the mode versus method-distinction would be levelled. Second, although in praxis IBE comprises all three modes (so pure forms thereof would be rare if modes operated jointly), one may nevertheless analytically distinguish these modes on grounds of theoretical significance. (In fact, scholars do so for induction and deduction.) Third, the claim that 'one may equate abduction with IBE because the latter follows upon the former in time' is false. For we saw that hypothesis-generation need not lead to hypothesis-evaluation. But without the temporal sense also a causal sense of 'follows' is unavailable, if temporal succession is necessary for causality.

These reasons speak against equating abduction and IBE. Nevertheless, we see one reason why abduction might be regarded as IBE, namely the impulse to obtain certainty. Irrespective of how certainty is achieved (if ever), the goal of IBE is to single out the "best" explanation; the goal of abduction, by contrast, is to generate plausible explanations for further testing. So abduction and IBE appear to pull in different directions, for abduction generates yet more of what IBE, as it were, must then "deal" with. So rather than appreciating that selecting the best hypothesis presupposes an exhaustive list of hypotheses, abduction may seem to increase uncertainty.

\section{Abductive Argument in Peirce's Sense}

\subsection{Overview}

The three argumentation schemes for abduction presented in Sect. 2 were seen to follow Harman's IBE model, as improved by Lipton, and to equate abduction and IBE. Also Wagemans offers a combined account, though he mentions a separate 
account of generative abduction. Since this risks diluting abduction as a theoretical category, and misrepresents Peirce's scholarship, we revisit his notion of abduction and propose a scheme for it (4.2), turn to four roles assigned to critical questions (CQs) (4.3), formulate CQs for the scheme (4.4), and compare them to Josephson and Josephson's (1994) criteria (4.5).

\subsection{The Abductive Argument Scheme}

The early Peirce proposed the following logical form for abduction, where ' $\mathrm{A}$ ' stands for 'antecedent' and ' $\mathrm{C}$ ' for 'consequent':

The surprising fact, $\mathrm{C}$, is observed;

But if A were true, $\mathrm{C}$ would be a matter of course,

Hence, there is reason to suspect that $\mathrm{A}$ is true. (Peirce, 5.189)

Peirce notes that "[...] A cannot be abductively inferred, or if you prefer the expression, cannot be abductively conjectured until its entire content is already present in the premiss, "if A were true, $\mathrm{C}$ would be a matter of course'" (Peirce, 5.189). ${ }^{7}$ Here A mentions either a rule or a case. Moreover, the conclusion is not exhausted by A, but contains 'there is a reason to', and hence "only infers a maybe" (Niiniluoto 1999, S439; see Peirce, 8.238).

Our proposed argument scheme for Peirce's sense of abduction resembles what Wagemans $(2014,5)$ calls "generative abduction." Likewise, we too draw on the pragma-dialectical approach to argument structure, where ' 1 ' represents the standpoint, '1.1a' and '1.1b' are premises, '1.1a-1.1b' is an unexpressed premise, stating "that, in principle, if the complex proposition $[1,1.1 \mathrm{a}, 1.1 \mathrm{~b}]$ is acceptable, then the standpoint is acceptable" (Andone 2015, 8). ${ }^{8}$ Our scheme differs from Wageman's (2014) in that we focus on the generative aspect of abduction, and also refine the critical questions:

1 There is a reason to suspect that the explanation $\mathrm{A}$ is true.

1.1a The surprising fact $\mathrm{C}$ is observed.

$1.1 \mathrm{~b}$ If explanation $\mathrm{A}$ were true, $\mathrm{C}$ would be a matter of course.

(1.1a-1.1b) (If the surprising fact of type $C$ [such as C] is observed, and if an explanation of type $A$ [such as A] were true, the surprising fact of type $C$ [such as C] would be a matter of course, then there is a reason to suspect that the explanation of type $A$ [such as $\mathrm{A}]$ is true.)

\footnotetext{
7 See Frankfurt (1958) and Anderson (1986) on whether, or not, to maintain that "if the new idea, or hypothesis, must appear in one of the premisses of the abduction, [then] it cannot be the case that it originates as the conclusion of such an inference, [since] it must have been invented before the conclusion was drawn" (Frankfurt 1958, 594).

8 In Pragma-dialectical notation, 'a', 'b', 'c', etc. stand for coordinative argumentation; brackets indicate unexpressed premises (see Andone 2016, 50; van Eemeren 2010). Moreover, "pragma-dialecticians opt for a general formulation of the unexpressed premise [as] this general premise is more informative than a more specific formulation [...]" (Andone 2015, 9; see van Eemeren and Grootendorst 1992, 60-66). Wagemans (2014) supplies the pragmatic optimum of the unexpressed premises, as "A explains (or causes) C," while we state the logical minimum.
} 
Besides the pragma-dialectical model offering "[a]n approach in which the structure of argumentation as well as the relation between critical questions [CQs] and the various arguments (premises) presented in the scheme are treated in a more systematic way [...]" (Wagemans 2014, 5; italics added), the model aligns well with the four roles of CQs proposed by Verheij (2003) (see our Sect. 4.3).

In proposing critical questions that stay true to Peirce, but also integrate useful elements from Josephson and Josephson's work-and hence Walton's (see Sect. 2.3)—it pays to heed Peirce's maxim:

If you carefully consider the question of pragmatism you will see that it nothing else than the question of the logic of abduction. That is, pragmatism proposes a certain maxim which, if sound, must render needless any further rule as to the admissibility of hypotheses to rank as hypotheses, that is to say, as explanations of phenomena held as hopeful suggestions; and furthermore this is all that the maxim of pragmatism pretends to do (Peirce, 5.196).

Peirce addresses the question "[w]hat should an explanatory hypothesis be to be worthy to rank as a hypothesis?" (ibid.) with the following remark: "Any hypothesis [...] may be admissible, in the absence of any special reasons to the contrary, provided it be capable of experimental verification, and only insofar as it is capable of such verification." He refers to this dictum as "[...] approximately the doctrine of pragmatism," and immediately raises the related question "[w]hat are we to understand by experimental verification," stating that "[t]he answer to that [question] involves the whole logic of induction" (Peirce, 5.197). So, in Peirce's view, a criterion for good abduction is that the hypothesis is open to experimental verification. But to in fact verify it goes beyond abduction.

Compared to Johnson \& Johnson's evaluative factors (listed below), the critical questions associated to the abductive argument scheme in Peirce's sense, therefore, must narrowly relate to the admissibility of an explanatory hypothesis, rather than to what Lipton called its loveliness or likeliness. For such criteria pertain to IBE.

\subsection{Four Roles for Critical Questions}

We seek to relate our own CQs for the abductive argument scheme to Verheij's four roles, or purposes, of CQs (Verheij 2003, 182f.):

1. To criticize a scheme's premises;

2. To point out exceptional situations where a scheme should not be used;

3. To point out the conditions for a scheme's use;

4. To point to other possible arguments relevant for a scheme's conclusion.

Though roles 2 and 3 may seem similar, role 2 "block[s] the use of the argumentation schemes" (Verheij 2003, 174), which arguably is what Pollock's undercutting defeaters do (Pollock 1987, 485; see Verheij 2006, 195). Role 3 cites conditions for deciding whether a scheme should be used (whether the usage itself is good or not). The four roles can be divided into two groups: role 1, 2, and 4 are 
internal, role 3 is external. The last role closely relates to the unexpressed premise in our scheme, ${ }^{9}$ whereas a CQ based on role 3 questions the scheme's applicability. ${ }^{10}$

\subsection{Critical Questions}

We propose two CQs related to premises 1.1a and 1.1b:

Is what we observed, $\mathrm{C}$, reliable?

If $\mathrm{A}$ were true, can $\mathrm{C}$ be deduced from it?

The term 'reliable' here means: (mostly) error-free; but see Goldman and Beddor (2016) for additional uses of it. Further, one might think the second CQ can simply be stated as 'Is A an explanation of C?' or 'Does the hypothesis explain the facts?' But "[i]n terms of pragmatism [...] any hypothesis must explain or account for the facts in the sense that they can be deduced from it" (Burks 1946, 306; italics added). Only if this CQ receives a positive answer is the use of the schema correct, so as to arrive at its conclusion, A.

The CQ regarding the scheme's conclusion (or the standpoint) is:

Is A testable and plausible (in the sense of supposed truth)?

This CQ addresses "the admissibility of hypotheses to rank as hypotheses" (Peirce, 5.196). Crucially, Peirce admits any experimentally verifiable hypothesis. It is tempting to avoid discussion of 'verifiable' by pointing, with Peirce, to the "whole logic of induction." Additionally, one might remark: whatever that logic's details, it cannot without circularity involve abduction. Of course, this won't do as a scholarly answer. It is nevertheless clear that the CQ must ask "Is A testable?"

As stated in Sect. 3.3, to suspend the problem of an infinite number of hypotheses, not all possible explanations but only plausible ones, which have "supposed truth," are related to our system of beliefs. All the same, to properly apply this CQ, 'testability' demands further specification, e.g., via (probabilistic versions of) verification or falsification.

The CQ related to the unexpressed premise, which provides the warrant and at the same time use-conditions for the scheme, is:

Can and should we use abduction in this situation?

\footnotetext{
${ }^{9}$ Feteris (2016) instead justifies the applicability of the scheme in a distinct step. This draws role 3 out from the scheme, as she needs to first determine the applicability (she uses 'appropriateness') of pragmatic argumentation as the main type of a context-specific prototypical pattern for legal hard cases (see van Eemeren 2016). Feteris's and Verheij's approaches are not in conflict; the latter is merely more general. Notice that the CQs related to role 3 should be answered first, and if the answer is negative, so is the overall evaluation.

${ }^{10}$ Verheij submits that " $P \mathrm{~s}$ are $Q \mathrm{~s}$ ' is [...] a condition for the use of the scheme [...], cf. Toulmin's warrant (1958)" (Verheij 2003, 180). But notice that, in Toulmin's sense, the statement ' $P$ s are $Q$ s' presents a backing rather than a warrant, and that the relationship between a warrant and a backing is not unique. (For the legitimation inference between warrant and backing, see Goodnight 1993). However, the condition for the use of the scheme must be a warrant, for it has to be a rule to decide all relevant cases (Toulmin 2003, 91; see Hitchcock 2003, 70).
} 
This CQ should be answered first, as it is a precondition for using the scheme. Obviously, the CQ is context-dependent, while the can- and the should-part might even be kept separate.

The CQ related to exceptional situations for using the scheme is:

Is what we observed, $\mathrm{C}$, complete?

If answered positively, then relevant exceptional circumstances cannot undercut the link between premises and conclusion.

After some rearrangement, the full list of CQs is:

CQ1: Can and should we use abduction in this situation?

CQ2: Is what we observed, $\mathrm{C}$, reliable? (Premise 1.1a)

CQ3: If A were true, can $\mathrm{C}$ be deduced from it? (Premise 1.1b)

CQ4: Is A testable and plausible (in the sense of supposed truth)? (Conclusion/ Standpoint)

CQ5: Is what we observed, C, complete? (Exceptional situation)

\subsection{Comparison with Josephson \& Josephson}

This in place, we briefly return to Josephson \& Josephson's evaluative factors.

1. Threshold How decisively does $\mathrm{H}$ surpass the alternatives?

2. Internal merit How good is $\mathrm{H}$ by itself, independently of considering alternatives.

3. Data reliability How trustworthy are data, respectively the processes by which data were obtained?

4. Exhaustiveness How much confidence is there that all plausible explanations have been considered.

5. Cost and Benefits Pragmatic considerations, including the costs of being wrong, and the benefits of being right.

6. Gravity of issue How strong is the need to reach a conclusion, especially considering the possibility of seeking further evidence before deciding.

It is easy to see that some of their six criteria pertain to the comparative quality of a focal hypothesis (as an internally merited, comparatively superior, and absolutely decisive explanation)—which to apply as criteria presupposes an evaluation, hence pertaining to IBE - or to the (dis-)utility of acting on that focal hypothesis at present. But these aspects do not relate Peirce's own sense of abduction. By contrast, the second, third and sixth of their evaluative factors are included in our CQs 2, 3 and 4.

\section{Conclusion}

Whether as an inference or as an argument externalizing it, abduction is relevant whenever data-saving hypotheses are needed. We reviewed three abductive argument schemes, and saw how philosophy of science scholarship (by Harman, Lipton, and others) progressively altered Peirce's sense of abduction, viz., the 
generation of testable explanatory hypotheses. In many contexts, abduction thus became a (near-)synonym for inference to best explanation (IBE).

It is this interpretation that surfaced in argumentation studies. But since IBE pertains to selecting among explanatory hypotheses, we proposed an alternative scheme (formulated in pragma-dialectical manner). This, we submit, accords better with the status abduction ought to have:

1 There is a reason to suspect that the explanation $\mathrm{A}$ is true.

1.1a The surprising fact $\mathrm{C}$ is observed.

$1.1 \mathrm{~b}$ If an explanation $\mathrm{A}$ were true, $\mathrm{C}$ would be a matter of course.

(1.1a-1.1b) (If the surprising fact of type $C$ [such as $C$ ] is observed, and if an explanation of type $A$ [such as $\mathrm{A}$ ] were true, the surprising fact of type $C$ [such as C] would be a matter of course, then there is a reason to suspect that the explanation of type $A$ [such as A] is true.)

We suggested these critical questions:

CQ1: Can and should we use abduction in this situation?

CQ2: Is what we observed, $\mathrm{C}$, reliable? (Premise 1.1a)

CQ3: If $\mathrm{A}$ were true, can $\mathrm{C}$ be deduced from it? (Premise 1.1b)

CQ4: Is A testable and plausible (in the sense of supposed truth)?

(Conclusion/standpoint)

CQ5: Is what we observed, C, complete? (Exceptional situation)

We saw how Peirce struggled, but managed to distinguish abduction from induction, by assuming types of reasoning based on the process of scientific inquiry: abduction arrives at a hypothesis; induction then tests it. Equating abduction with IBE, or understanding them an inseparable parts, unnecessarily complicates evaluation by levelling the status of abduction as a third reasoning mode (besides deduction and induction), which itself features in IBE. We therefore suggest retaining abduction alongside IBE, as related but distinct categories.

Acknowledgements We thank Xiong Minghui and Xie Yun for useful comments on a previous version of this manuscript. S.Y. acknowledges support from the International Program for Ph.D. Candidates, Sun Yat-Sen University. F.Z. acknowledges an "Understanding China"-fellowship from the Confucius Institute (HANBAN), as well funding from the European Union's FP 7 framework program (No. 1225/02/ 03) and the Volkswagen Foundation (No. 90,531).

Open Access This article is distributed under the terms of the Creative Commons Attribution 4.0 International License (http://creativecommons.org/licenses/by/4.0/), which permits unrestricted use, distribution, and reproduction in any medium, provided you give appropriate credit to the original author(s) and the source, provide a link to the Creative Commons license, and indicate if changes were made.

\section{References}

Aliseda, A. 2006. Abductive Reasoning. Logical Investigations into Discovery and Explanation (Syntheses Library), vol. 330. Berlin: Springer. 
Anderson, D.R. 1986. The evolution of Peirce's concept of abduction. Transactions of the Charles S. Peirce Society 22: 145-164.

Andone, C. 2015. Pragmatic argumentation in European practices of political accountability. Argumentation 29: 1-18.

Andone, C. 2016. Argumentative patterns in the political domain: The case of European parliamentary committees of inquiry. Argumentation 30: 45-60.

Bex, F., and B. Verheij. 2012. Solving a murder case by asking critical questions: An approach to factfinding in terms of argumentation and story schemes. Argumentation 26: 325-353.

Bex, F., and B. Verheij. 2013. Legal stories and the process of proof. Artificial Intelligence and Law 21: 253-278.

Burks, A.W. 1946. Peirce's theory of abduction. Philosophy of Science 13: 301-306.

Bybee, M.D. 1996. Abductive inferences and the structure of scientific knowledge. Argumentation 10: 25-46.

Campos, D.G. 2011. On the distinction between Peirce's abduction and Lipton's inference to the best explanation. Synthese 180: 419-442.

Douven, I. 2011. Abduction. In The Stanford Encyclopedia of Philosophy. Winter 2016 ed, ed. E.N. Zalta. http://plato.stanford.edu/entries/abduction/.

Feteris, E.T. 2016. Prototypical argumentation patterns in a legal context: The role of pragmatic argumentation in the justification of judicial decisions. Argumentation 30: 61-79.

Frankfurt, H.G. 1958. Peirce's notion of abduction. The Journal of Philosophy 55: 593-597.

Goldman, A., and Beddor, B. 2016. Reliabilist epistemology. In The Stanford Encyclopedia of Philosophy. Winter 2016 ed, ed. E.N. Zalta. https://plato.stanford.edu/archives/win2016/entries/ reliabilism/.

Goodnight, T. 1993. Legitimation inference: An additional component for the Toulmin model. Informal Logic 15: 1-15.

Hitchcock, D.L. 2003. Toulmin's warrants. In Anyone Who has a View. Theoretical Contributions to the Study of Argumentation, ed. F.H. van Eemeren, et al., 69-82. Dordrecht: Kluwer.

Hitchcock, D.L., and J.H.M. Wagemans. 2011. The pragma-dialectical account of argument schemes. In Keeping in Touch with Pragma-Dialectics, ed. E.T. Feteris, B.J. Garssen, and A.F. Snoeck Henkemans, 185-205. Amsterdam: John Benjamins.

Hintikka, J. 1998. What is abduction? The fundamental problem of contemporary epistemology. Transactions of the Charles S. Peirce Society 34: 503-533.

Harman, G. 1965. The inference to the best explanation. Journal of Philosophy 74: 88-95.

Josephson, J.R., and S.G. Josephson. 1994. Abductive Inference: Computation, Philosophy, Technology. New York: Cambridge University Press.

Lipton, P. 1991. Inference to the Best Explanation. London: Routledge.

Magnani, L. 2001. Abduction, Reason and Science. Processes of Discovery and Explanation. Dordrecht: Kluwer.

Oddie, G. 2016. Truthlikeness. In: The Stanford Encyclopedia of Philosophy. Winter 2016 ed, ed. E.N. Zalta. https://plato.stanford.edu/archives/win2016/entries/truthlikeness/.

Niiniluoto, I. 1999. Defending abduction. Philosophy of Science 66: S436-S451.

Peirce, C.S. 1931-1958. Collected Papers of Charles Sanders Peirce, vol. 1-8, eds. P. Weiss, C. Hartshorne, \& A.W. Burks. Cambridge, MA: Harvard University Press.

Perelman, C., \& Olbrechts-Tyteca, L. 1969. The New Rhetoric. A Treatise on Argumentation (trans: Wilkinson, J. and Weaver, P.). Notre Dame: University of Notre Dame Press (Original work published 1958).

Pollock, J.L. 1987. Defeasible reasoning. Cognitive Science 11: 481-518.

Preyer, G., and D. Mans. 1999. On contemporary developments in the theory of argumentation. Protosociology 13: 3-13.

Psillos, J. 2000. Causality: Models, Reasoning, and Inference. Cambridge: Cambridge University Press. Schurz, G. 2008. Patterns of abduction. Synthese 164: 201-234.

Shelley, C.P. 1996. Visual abductive reasoning in archaeology. Philosophy of Science 63: 278-301.

Spohn, W. 2012. The Laws of Belief: Ranking Functions and Their Applications. Oxford: Oxford University Press.

Thagard, P. 1992. Conceptual revolutions. Princeton: Princeton University Press.

Thagard, P. 1999. How scientists explain disease. Princeton: Princeton University Press.

Thagard, P. 2000. Coherence in thought and action. Cambridge, MA: MIT Press. 
Thagard, P. 2007. Abductive inference: From philosophical analysis to neural mechanisms. In Inductive Reasoning: Experimental, Developmental and Computational Approaches, ed. A. Feeney and E. Heit, 226-247. Cambridge: Cambridge University Press.

van Eemeren, F.H., and R. Grootendorst. 1992. Argumentation, Communication, and Fallacies: A Pragma-Dialectical Perspective. Hillsdale: Lawrence Erlbaum.

van Eemeren, F.H., and R. Grootendorst. 2004. A Systematic Theory of Argumentation. The PragmaDalectical Approach. Cambridge: Cambridge University Press.

van Eemeren, F.H. 2010. Strategic Maneuvering in Argumentative Discourse. Extending the PragmaDialectical Theory of Argumentation. Amsterdam: John Benjamins.

van Eemeren, F.H., B. Garssen, E.C.W. Krabbe, F.S. Henkemans, B. Verheij, and J.H.M. Wagemans. 2014. Handbook of Argumentation Theory. Dordrecht: Springer.

van Eemeren, F.H. 2016. Identifying argumentative patterns: A vital step in the development of pragmadialectics. Argumentation 30: 1-23.

Verheij, B. 2003. Dialectical argumentation with argumentation schemes: An approach to legal logic. Artificial Intelligence and Law 11: 167-195.

Verheij, B. 2006. Evaluating arguments based on Toulmin's scheme. In Arguing on the Toulmin Model: New Essays in Argument Analysis and Evaluation, ed. D. Hitchcock and B. Verheij, 181-202. Dordrecht: Springer.

Wagemans, J.H.M. 2014. The assessment of argumentation based on abduction. In Virtues of Argumentation: Proceedings of the 10th International Conference of the Ontario Society for the Study of Argumentation (OSSA), 22-26 May 2013, ed. D. Mohammed and M. Lewiński, 1-8. Windsor, ON: OSSA.

Walton, D. 1996. Argumentation Schemes for Presumptive Reasoning. Mahwah: Lawrence Erlbaum.

Walton, D. 2001. Abductive, presumptive and plausible arguments. Informal Logic 21: 141-169.

Walton, D., Ch. Reed, and F. Macagno. 2008. Argumentation Schemes. Cambridge: Cambridge University Press.

Williamson, J. 2003. Review: Abduction, reason, and science-Processes of discovery and explanation. British Journal for the Philosophy of Science 54: 353-358.

Woods, J. 2013. Errors of Reasoning: Naturalizing the Logic of Inference. London: College Publications.

Zenker, F. 2011. Deduction, induction, conduction. An attempt at unifying natural language argument structures. In Conductive Argument: An Overlooked Type of Defeasible Reasoning, ed. J.A. Blair and R.H. Johnson, 74-85. London: College Publications. 